\title{
REMOTELY CONTROLLED CAR SPEED GOVERNOR
}

\author{
ALONGE OLUWASANMI IYIOLA ${ }^{1 *}$, ABIOLA OLURANTI ADETUNJI', \\ OKEDIJI ADEBUNMI PETER ${ }^{1}$, ALABI ISMAILA OLANREWAJU ${ }^{1}$ \\ ${ }^{1}$ Department of Mechanical and Automotive Engineering, Elizade University, P.M.B., 002, \\ Ilara-mokin, Ondo State, Nigeria
}

\begin{abstract}
This study modifies a car speed limiting device with a view to avoiding car over speeding. The speed limiter was modified by incorporating a carrier chip to coordinate the activities of the speed limiter. When the car speed exceeded the designed speed limit, the speed governor came into action and restricted the car from going beyond the pre-set speed by actuating the relay. Warning signal in the form of alarm was activated, and the receiver sent a message to the owner. The study concluded that the modified speed governor design is better, safer and remotely controlled compared to the existing design.
\end{abstract}

Keywords: car, speed, speed limiter, relay, alarm, message

\section{INTRODUCTION}

Road accidents have become something normal due to its consistent happening and ubiquitousness. Even in our present world, we believe any mechanical device could fail or show sign of misbehavior, especially if not properly manage. Every minute someone is killed or wounded seriously on the major roads because of terrible mishaps [1]. A study by International Road Federation (IRF) reveals that about 2.4 million people have died in highway accident worldwide, with over 1.3 million fatalities per year and daily record of 3000 deaths [2]. This is a worldwide pestilence practically identical to Malaria or Tuberculosis, which go after the youthful, poor people and the defenseless [3]. The primary explanation behind these mischances is the fast and careless driving of motorist. The World Health Organization raised an alarm on this figure and believes that it may increase to 1.9 million if deliberate and solid action is not taken [4]. Safety has become principal focus of government agencies and private organizations concerned with transportation. In Nigeria, the Federal Road Safety Commission (FRSC) is the government agency with legislative regulatory for road safety. Nigeria is Africa's most populous country with a surface area of 910,771 square kilometers and an estimated human population of about 167 million people and over 7.6 million vehicles with a total length of about 194,000 kilometers and the country has suffered severe loss of manpower and economy to fatal car accidents [5]. Undoubtedly, this population create immense pressure that contributes to the high road traffic accidents in the country [6].

The factors that lead to car accidents in Nigeria are human, mechanical and environmental. Up to $90 \%$ of injuries are human factors while the mechanical and environmental factors sum-up to 10\% [7]. Human factors include visual acuteness, exhaustion of driver, confusion of road signs and regulations, analphabetism, health issues, excessive speed, substance addiction and overconfidence in driving. Mechanical causes include inadequate vehicle maintenance, pneumatic blowouts, bad lighting, and vehicle breakdown without sufficient warning while environmental factors are summed up in heavy rainfall, halibut, sunlight, heavy wind, potholes and unpaved roads. These factors contributed to the high prevalent rate of fatal car accidents in Nigeria either independently or collectively [8]. With the deadly crashes encountered everywhere throughout the world, vehicle

\footnotetext{
*Corresponding author, email: alongeoluwasanmi@gmail.com

(C) 2020 Alma Mater Publishing House
} 
safety has been set up to check them. One of the approaches to lessen such vehicle crashes is to avoid over speeding in streets and expressways.

Vehicle safety is a basic issue in the car business and there are two existing sorts of vehicle security frameworks: dynamic wellbeing and detached wellbeing frameworks [9]. Dynamic security keeps accidents from happening and detached frameworks are worked in the auto to ensure the tenants or clients after the mishap has happened. Dynamic security frameworks contribute considerably to lessening of extreme wounds and fatalities in rush hour gridlock and as the level of dynamic wellbeing innovation in vehicles is expanded, the quantities of mischances diminish. Vehicle speed sensor is a standout amongst the most critical gadgets in the dynamic security framework [10]. It is a gadget in vehicles that restricts the speed of a vehicle. Vehicle devices today assume a key part in the ergonomics and safety highlights. The appearance of electronically controlled actuators has added to development of vehicle sensors [9]. A portion of the devices set up to control inordinate speeding incorporate Intelligent Speed Adaptation (ISA) devices [10] and the speed governors. The ISA gadget screens the speed of the vehicle. The ISA devices are actualized utilizing worldwide situating system collectors, radio recurrence beneficiaries or optical acknowledgment system which requires extensive infrastructural venture.

A few vehicle speed sensor systems have been created for use inside the vehicle for speed checking and control purposes. Customary vehicle speed sensor presently being used incorporate Variable Reluctance (VR) sensor. The yield of VR sensor is a simple flag whose frequency and amplitude are corresponding to vehicle speed. Another issue with the current electronic vehicle speed governors is that fuel supply to the motor is all of a sudden cut when vehicle top speed is accomplished due to the on/off control strategy which results to vehicle jerking. The automobile is likewise one of the primary methods for transportation, and individuals make broad utilization of it for the duration of their lives. This reason, among others, justifies the need of use of the advances in sensors, instrumentation, and control in vehicles with the goal of enhancing road safety. Most work centered on the effect of speed limit on accidents and causalities reduction [11].

Few articles are available that concern the technical aspect of the speed limiting system. Most of the articles covered the technical perspectives of the automotive speed governor system over the last few years. An order of speed limiting device has been introduced demonstrating the advantages and disadvantages each type [12]. He found out that appropriately design ISA can be exceedingly successful in urging drivers to observe speed limits and ought to be supported by governments. Another infrastructure to vehicles communication and control system for smart speed governor has also been exhibited, which depends on Radio Frequency Identification (RFID) technology for the detection of traffic signals [5]. Their outcomes recommended that an automatic intelligent control system can be used to keep any sudden activity conditions and enhance the safety of the occupants of the vehicle.

A design to control the speed of the automobiles at remote places for fixed time has been presented [13]. In their proposed model, the pedal position is located with the microcontroller and after that exchanges appropriate signal to the Electronic Control Unit (ECU) that thus controls the cars' throttle position. They expressed that their theoretical study needs further extension to more than one vehicle. The objectives of this work are to modify a speed governor by adding a speed notifier and SMS controller into it and evaluate a prototype of the device through experiments.

\subsection{Types of road speed limiter}

1.1.1. Functionality based

Top-speed limiting: It stops the vehicle from going beyond a speed limit. Most of the current engine management systems have high-speed configuration but are generally far beyond national maximum speed limits and cannot be considered a safety tool.

Speed alarm and speed limit set by the driver: It notifies the driver if the pre-set speed is reached. This is common in some automobile. This also prohibits the car from travelling over the preset speed, except for temporary cross-ride situations. This is also referred as "Adjustable Speed Limitation Function (ASLF)".

Smart speed alarm and speed limiter: The system "knows" through an application like google map, road segment speed limit and the travel direction warn the driver when the speed is exceeded by sound warning or combination of sound warning, a visual signal, or a vibrating throttle pedal. This also prevents acceleration of the vehicle above this speed. 


\subsubsection{Based on the control technique}

Throttle control: the throttle control is a type of technique used in limiting the speed of a vehicle through throttle body of the engine. A throttle body is the intake system component in fuel-injected engines that the drivers controls with the accelerator. The throttle regulates or limits the amount of air that enters the combustion chamber with the fuel delivered from the injector.

Direct fuel control: the direct fuel control is the most type technique used to regulate the speed of a vehicle. Also, the fuel control is the most effective of all types. In this type of method, the fuel is the source of control. The speed is limited by reducing the amount of fuel that is released into the combustion chamber for combustion.

Electronic speed governor: in this type, electric signal is utilized by using a magnetic pick-up sensor. The magnetic pick-up sensor is installed alongside a drive shaft gear made of material that responds to a magnetic field. As each gearing tooth passes the sensor, the gear interrupts the sensors magnetic field. This, thus, creates an alternating current signal, which compares to the speed of the shaft. The signal is sent to the electronic control module to build up the measure of fuel that ought to be infused to the combustion chamber of the engine.

\subsection{Vehicle speed limiting system}

The basic measurement system consists mainly of three blocks: sensing element, signal conditioning element and signal processing element. An electronic speed limiter/governor contains three key components in particular the vehicle speed sensor, Electronic Control Unit (ECU) and a fuel flow control valve. The speed sensor creates electronic pulses in relation to the vehicle speed and transmits the same to the ECU. In this examination, the sensing component convert the non-electrical signal (mechanical rotational motion) into electrical signal (voltage pulses). The reason for the signal conditioning component is to convert the variety of electrical signal into a voltage level suitable for additionally preparing. This is accomplished using amplifier circuit and digital logic circuit. The following stage is the signal condition component which is a microcontroller which takes the output of the signal conditioning component and convert it into a shape appropriate for presentation and different uses (display, recording and feedback control). Based on the installed algorithm, the electronic control unit processes the speed of the vehicle also, persistently monitors the same. At whatever point the vehicle accomplishes the most extreme set speed, the electronic control unit enacts the actuator which directs the fuel stream and henceforth the vehicle speed is constrained.

\section{EXPERIMENTAL SETUP}

Materials used are speed limiting device, relay, connecting cables, GPS antenna while tools used are cutting plier, testing lamp, razor blade and black tape.

\subsection{Description of major components}

Speed limiting device: speed limiter is an electronic/electro-mechanical device fitted on a vehicle with the purpose of regulating the maximum speed of a vehicle to a set limit. A speed limiter is shown in Figure 1. Table 1 shows the speed limit for vehicles in Nigeria [14]. The speed limiter used in this work was pre-set to $95 \mathrm{~km} / \mathrm{h}$ and programmed with the receiver phone number. Speed Limiters are of different types based on the vehicle category on which it is used. The two most important types are the Drive by Wire System (RDPS) and the fuel type system. The fuel type system was used in this project. The speed limiter was built to have a port for the GPS antenna and the GSM antenna for receive signal. It also has another cable port for the connection of the wire that would be connected to the vehicle system.

Table 1. Speed limits for vehicles in $\mathrm{km} / \mathrm{hr}$.

\begin{tabular}{|l|c|c|c|}
\hline Types of vehicles & Build-up & Highway & Express-way \\
\hline Motorcycles & 50 & 50 & - \\
\hline Private cars & 50 & 80 & 100 \\
\hline Taxis \& buses & 50 & 80 & 90 \\
\hline Tankers \& trailers & 45 & 50 & 60 \\
\hline Two vehicle (While Towing) & 45 & 45 & 45 \\
\hline Two vehicle (not Towing) & 50 & 60 & 70 \\
\hline
\end{tabular}


Connection cables: the connection cables were used to connect the speed limiter to the relay and to the vehicle. The connection cable had different cables with different colours on it, namely: blue, white, black, red, brown and yellow.

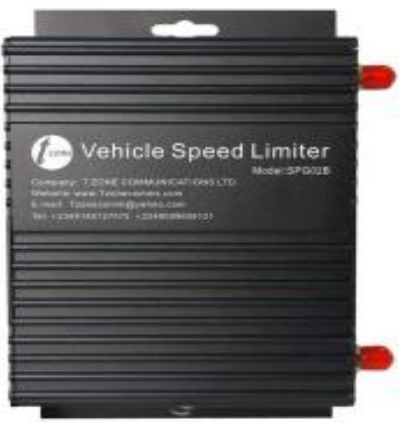

Fig. 1. Speed limiter.

Relay: is a switch that opens and closes circuit electromechanically or electronically. The relay used controls one electrical circuit by opening and closing contact in another circuit. The relay came with four (4) wires, two (2) thick green wires, a red wire and black wire. The relay is shown in Figure 2 (a). GPS and GSM antenna: the Global Positioning System is a worldwide radio-navigation system formed from a constellation of 24 satellites that continuously orbit the earth. All GPS receivers use an antenna to receive these signals. The GPS Antenna is shown in Figure 2 (b). GSM antenna is an antenna to receive GSM signal to the device. It is as shown in Figure 2 (c).

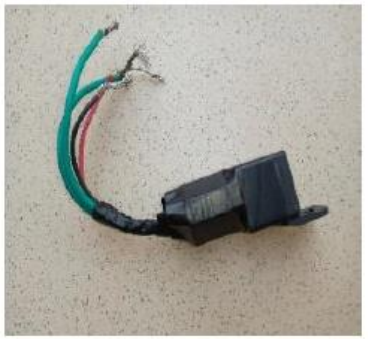

(a)

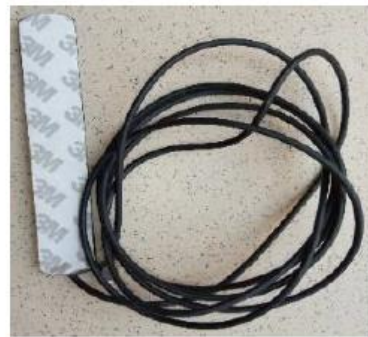

(b)

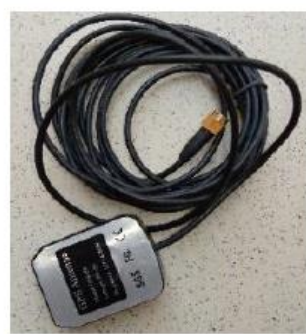

(c)

Fig. 2. Connection cables: (a) Relay (b) GPS Antenna (c) GSM Antenna.

The specification of cars used in this research are shown in Table 2 and 3. First thing done was to identify the fuel line cable (yellow cable with green stripes) using a Tester which is a device used to test for the flow of current in a wire or circuit. The fuel line cable was cut into two, making the wires one carrying current from the source and the other without any current in it. The divided wires were then connected to the relay. Connection of the relay to the fuel line was carried out by connecting the two thick green wires from the relay to the two ends of the fuel line cables. One of the thick green cables was connected to the fuel line cable from the power source and the other green cable to the second wire of the fuel line.

Table 2. Engine specification (HONDA ACCORD).

\begin{tabular}{|l|l|}
\hline Fuel tank capacity & $17.1 \mathrm{Gal}$ \\
\hline EPA* mileage estimates & 26 city/ 34 Highway \\
\hline Base engine size & 2.4 liters \\
\hline Base engine type & $\mathrm{I}-4$ \\
\hline Horsepower & $160 \mathrm{Hp}$ \\
\hline Horsepower rpm & 5,500 \\
\hline Torque & $161 \mathrm{Lb}-\mathrm{Ft}$ \\
\hline Torque rpm & 4,500 \\
\hline Maximum Towing capacity & $1,000 \mathrm{Lbs}$ \\
\hline Drive type & Front wheel \\
\hline
\end{tabular}

*EPA- Environmental Protection Agency

The black wire from the relay to the black wire of the connection cable were joined together because the black wire is the grand wire. Both black wires were connected to any other grand in the vehicle. The red wire from the 
relay was connected to the brown cable from the connection cable. At the end the connection cable is plugged into the speed limiter. The red and white wire from the connection cable is connected to the thick green cable of the relay (the current source). The GPS and GSM antennas were connected to the speed limiter.

Table 3. Engine specification (TOYOTA COROLLA).

\begin{tabular}{|l|l|}
\hline Fuel tank capacity & $17.1 \mathrm{Gal}$ \\
\hline EPA mileage estimates & 26 city/ 34 Highway \\
\hline Base engine size & $1.8 \mathrm{Liters}$ \\
\hline Base engine type & $\mathrm{I}-4$ \\
\hline Horsepower & $132 \mathrm{Hp}$ \\
\hline Horsepower rpm & 6,000 \\
\hline Torque & $128 \mathrm{Lb}-\mathrm{Ft}$ \\
\hline Torque rpm & 4,400 \\
\hline Maximum Towing capacity & $950 \mathrm{Lbs}$ \\
\hline Drive type & Front wheel \\
\hline
\end{tabular}

*EPA- Environmental Protection Agency

\section{RESULTS AND DISCUSSION}

\subsection{Honda Accord and Toyota Corolla response}

Table 4 and Table 5 show the interrelation between the car speed, engine speed, speed limiter, alarm and the receiver for Honda Accord and Toyota Corolla, respectively. Figure 3 shows the flow chart response of the two vehicles and different instances. They basically show the response of each component as the car speed changes. The engine speed in the case of Toyota Corolla was quite different from Honda Accord due to some factors like engine capacity, vehicle weight, and material selection. The two vehicles showed similar response to the speed limiter, alarm, and receiver. Figure 4 shows the histogram of car speed against speed limiter for Honda Accord and Toyota Corolla.

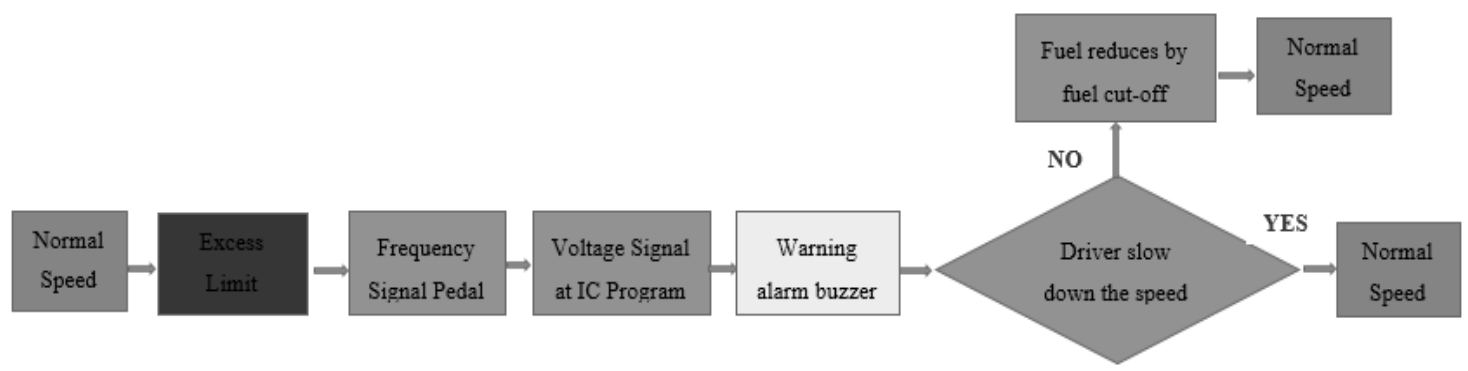

Fig. 3. Flow chart of vehicles responses at different instances.

Table 4. Interrelation between car speed and components for Honda Accord.

\begin{tabular}{|c|c|c|c|c|}
\hline $\begin{array}{c}\text { Car speed } \\
(\mathbf{k m} / \mathbf{h})\end{array}$ & $\begin{array}{c}\text { Engine speed } \\
(\text { Rev/min })\end{array}$ & Speed limiter & Alarm & Receiver \\
\hline 0 & 1000 & On (NA) & No & No \\
\hline 20 & 1100 & On (NA) & No & No \\
\hline 40 & 1500 & On (NA) & No & No \\
\hline 60 & 2000 & On (NA) & No & No \\
\hline 80 & 2500 & On (NA) & No & No \\
\hline 95 & 3000 & On (NA) & Yes & Yes (Msg) \\
\hline
\end{tabular}

*NA-Not Active, Msg- Message

At $0 \mathrm{~km} / \mathrm{h}$, the engine was idle. There was no load on the engine yet. Speed limiter was on but was not active because the speed has not been accomplished at which it will be active. At $20 \mathrm{~km} / \mathrm{h}$, Engines of the two vehicles started running at speed higher than $0 \mathrm{~km} / \mathrm{h}$ because load has been applied to it (Transmission was on drive). At $20 \mathrm{~km} / \mathrm{h}$, the speed limiter was on but was not active. Tracker was able to get signal and vehicles were able to be tracked at this speed. At $40 \mathrm{~km} / \mathrm{h}$, vehicle was moving at the constant speed while the speed limiter was not active but on. Tracker from the speed limiter was on and was able to track the vehicles (Honda Accord and Toyota Corolla) at that speed. At $60 \mathrm{~km} / \mathrm{h}$, no activity from the speed limiter aside the tracker been able to locate 
the exact location of vehicle at that point. At $80 \mathrm{~km} / \mathrm{hr}$., vehicle approaches maximum speed limit and speed limiter still not responsive while it is on. At $95 \mathrm{~km} / \mathrm{h}$, Engine of each car running at higher speeds, the speed limiter became active immediately it sensed the pre-set speed, reduced the current in the flow line circuit leading to reduction in the flow rate of the fuel being supplied to the combustion chamber making the mixture a lean mixture and limits the speed of the vehicle at $95 \mathrm{~km} / \mathrm{h}$. The tracker was able to track the vehicles location as well. When trying to exceed the pre-set car speed, the car refuses to exceed the speed because of the shortage in current of the flow line.

Table 5. Interrelation between car speed and components for Toyota Corolla.

\begin{tabular}{|c|c|c|c|c|}
\hline $\begin{array}{c}\text { Car speed } \\
(\mathrm{km} / \mathrm{h})\end{array}$ & $\begin{array}{c}\text { Engine speed } \\
(\mathrm{Rv} / \mathrm{min})\end{array}$ & Speed limiter & Alarm & Receiver \\
\hline 0 & 1100 & On (NA) & No & No \\
\hline 20 & 1300 & On (NA) & No & No \\
\hline 40 & 1500 & On (NA) & No & No \\
\hline 60 & 2100 & On (NA) & No & No \\
\hline 80 & 2400 & On (NA) & No & No \\
\hline 95 & 2800 & On (NA) & Yes & Yes (Msg) \\
\hline
\end{tabular}

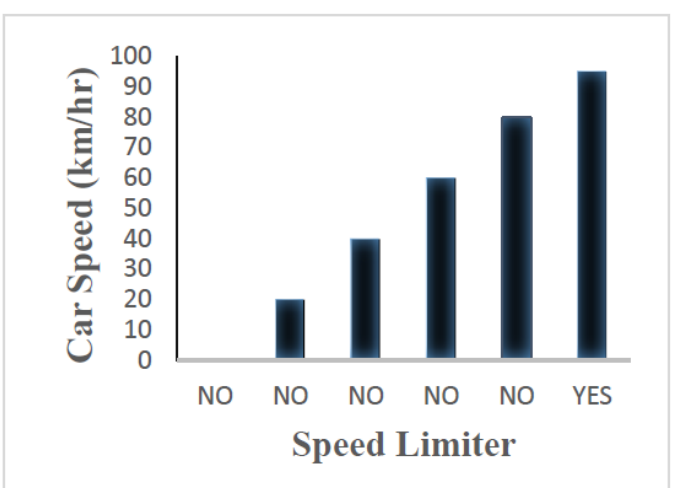

Fig. 4. Histogram of car speed against speed limiter for Honda Accord and Toyota Corolla.

Figure 5 shows the effect of car speed on the receiver for the two vehicles. As the speed of the car increases and approaches the maximum speed pre-set already in the speed limiter, the receiver responded variably. At $0 \mathrm{~km} / \mathrm{h}$ when the vehicle is idle, the receiver is on but not responsive at $0 \mathrm{~km} / \mathrm{hr}$. At $20 \mathrm{~km} / \mathrm{h}$, the engine was under load and vehicle was moving and yet the receiver is still not responded. At $40 \mathrm{~km} / \mathrm{h}$, the vehicle was still being driven and no output from the receiver from the speed limiter. At $60 \mathrm{~km} / \mathrm{h}$, receiver was on but no output from it. At 80 $\mathrm{km} / \mathrm{h}$, the vehicle was approaching the maximum speed limit and receiver was yet to respond to the speed at which the vehicle was been driven at. At $95 \mathrm{~km} / \mathrm{h}$, receiver is fully functional and responsive. The speed limiter stored the data to its history and when the network was restored, the speed limiter sent the message through the carrier component to the owner's phone as a text message as shown in Figure 6 and at that time the message was seen from the owner's phone. The vehicle was shut down by sending a code " $\langle\mathrm{SABO} * \mathrm{STP}\rangle$ " and a confirmation message saying "lock car successful" was received as shown in Figure 7, then vehicle shut down immediately. The vehicle started again as the owner restores the vehicle by sending "〈SABO*RES〉" and the owner (person sending the message receives a message too saying "unlocked successfully" as shown in Figure 8, then the vehicle will start again.

Figure 9 shows the response of the alarm at different car speed for the two vehicles. The alarm is the sound notifier that alerts the driver when the vehicle approaches or reaches the maximum pre-set speed on the speed limiter. At $0 \mathrm{~km} / \mathrm{h}$, car was on and running but alarm wasn't ringing. At $20 \mathrm{~km} / \mathrm{h}$, vehicle was moving, and alarm wasn't responsive. At $40 \mathrm{~km} / \mathrm{h}$, still running the car and the speed limiter was still not responsive. At $60 \mathrm{~km} / \mathrm{h}$, vehicle was still working and running but the alarm was not working. At $80 \mathrm{~km} / \mathrm{h}$, vehicle approached maximum speed and the alarm was yet to respond. The alarm started working when speed exceeded $80 \mathrm{~km} / \mathrm{h}$ and above. The sound became more pronounced when the speed got closer to the maximum speed. At $95 \mathrm{~km} / \mathrm{h}$, the car was at its maximum speed and the alarm was beeping continuously till the speed drops below the pre-set speed. When the speed drops below the maximum speed, the alarm reduced gradually. Between the speeds of 0-80 $\mathrm{km} / \mathrm{h}$, the alarm is inactive. 


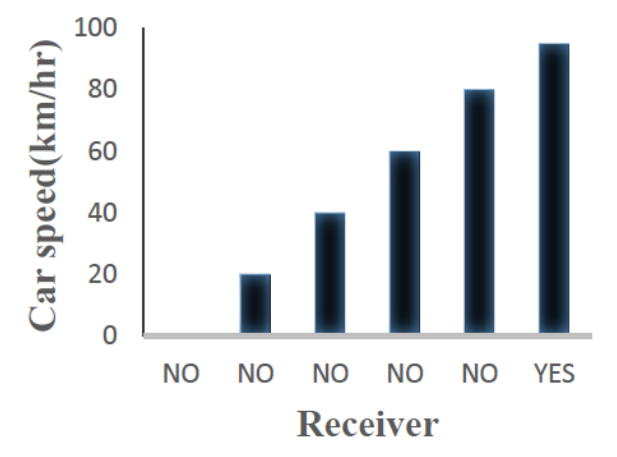

Fig. 5. Histogram of car speed against receiver for Honda Accord and Toyota Corolla.

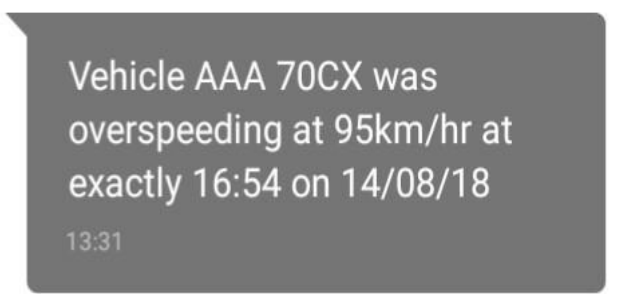

Fig. 6. Message from the receiver.

14:18,10 Auguus1 2078
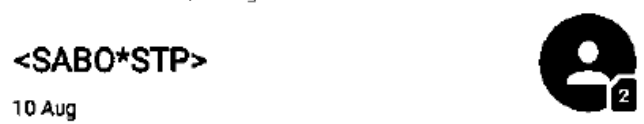

Lock car success!

Fig. 7. Message from the speed limiter after sending the STOP code.

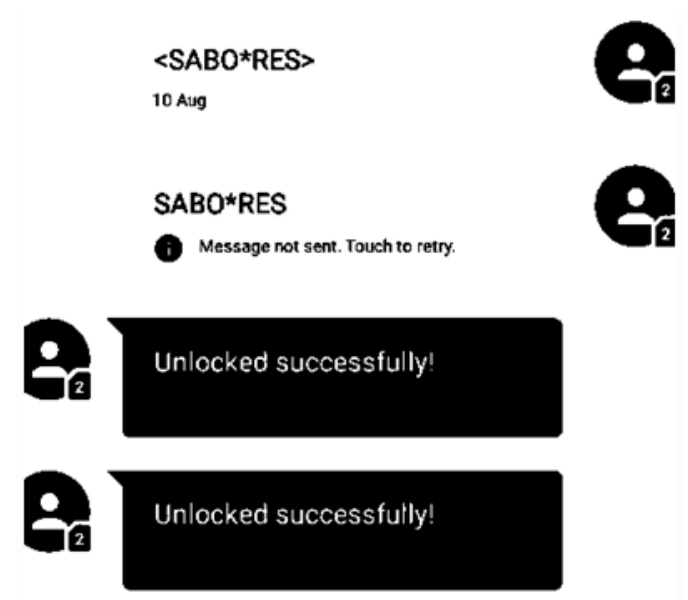

Fig. 8. Message gotten after sending restore code. 


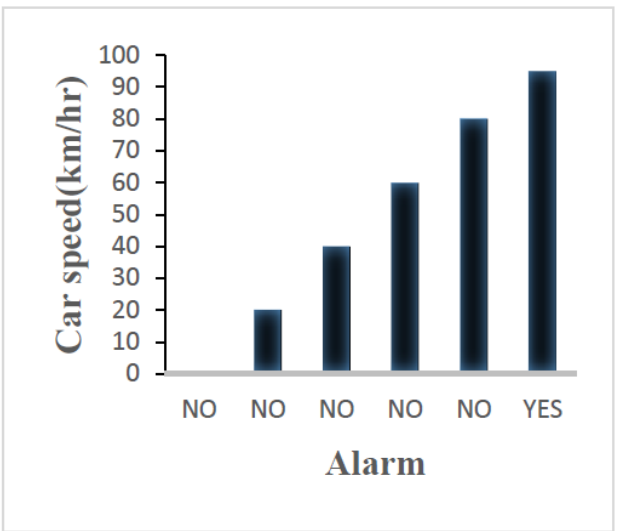

Fig. 9. Histogram of car speed against alarm for Honda Accord and Toyota Corolla.

\section{CONCLUSIONS}

This project has improved an existing speed limiting system by adding a notifier and SMS controller. The prototype programmed to limit speed at Federal Road Safety maximum speed at highway to be $95 \mathrm{~km} / \mathrm{h}$ was able to limit vehicle speed at its maximum speed $(95 \mathrm{~km} / \mathrm{h})$. The transmitted alarm sounds when the vehicle approaches $95 \mathrm{~km} / \mathrm{hr}$. and the receiver also gives or sends a text message when the car gets to its maximum speed, alerting the owner the speed activity of the vehicle. The relay, showed that once the speed drops below 95 $\mathrm{km} / \mathrm{h}$ the engine picks up again. The improvement basically provided an economic solution to deadly car crashes, save vehicle fuel consumption, and also monitor the activities of the driver. The project was focused more on limiting the speed of the vehicle and informing the owner about vehicle over-speeding activities. The project can further be improved by considering the system with google map road speed limits to know areas with their speed limits.

\section{REFERENCES}

[1] Ahmed, F.A., Talal, S.M., Proposed simple electro-mechanical automotive speed control system, American Journal of Aerospace Engineering, vol. 2, 2015, p. 1-10.

[2] http://www.irf.global/assets/annual-reports/2018-IRF-Annual-Report.pdf (05.07.2018).

[3] Varshith, H., Navale, D.J., Automobile speed limiter and reliever for automobiles, PES Institute of Technology and Management, Shivamogga, Project, 2011.

[4] https://tribuneonlineng.com/tag/federal-road-safety-corps-frsc/page/4/ (20.08.2018).

[5] Sumaila, A.F., Road crashes trends and safety management in Nigeria, Journal of Geography and Regional Planning, vol. 6, no. 3, 2013, p. 53-62.

[6] https://frsc.gov.ng/presidentroadmap.pdf (05.07.2018).

[7] Assum, T., Road safety in Africa: appraisal of road safety initiatives in five African countries, Sub-Saharan Africa Transport Policy Program, vol. 33, 1998.

[8] Ukoji, V.N., Trends and patterns of road accidents in Nigeria (June 2006 - May 2014), IFRA-Nigeria Working Papers Series, no. 35, 2014.

[9] Ogasawara, I., Ueno, S., Preparation and properties of amorphous wires, IEEE Transactions on magnetics, vol. 31, no. 2, 1995, p. 1219-1223.

[10] Fleming, W.J., Overview of automotive sensors, IEEE Sensors Journal, vol. 1, no. 4, 2001, p. $296-308$.

[11] Han, M., Liang, D.F., Deng, J., Sensor development using its unusual properties of copper based amorphous soft magnetic wire, Journal of Materials Science, vol. 40, no. 21, 2005, p. 5573-5580.

[12] Croitoru, B., Tulbure, A., Abrudean, M., Microcontroller- based multiple platform PWM signal generation procedures for industrial use, Automation, quality and testing, robotics, IEEE International Conference, 2014.

[13] Burje, S.R., Kulkarni, S.A., Dhande, N.B., Design and development of microcontroller based electronic speed governor for genset automotive engine, International Journal of Engineering and Science, vol. 1, 2012, p. 26-33.

[14] http://www.highwaycode.com.ng/ (15.06.2018). 